\title{
THE INFLUENCE MEDIA OF LEARNING BASED MACROMEDIA FLASH TO KNOWLEDGE ABOUT TAX ON STUDENT SMA SIDOARJO
}

\begin{tabular}{|c|c|}
\hline \multicolumn{2}{|c|}{$\begin{array}{c}\text { Yuni Purnama Sari }{ }^{1} \text { Irviandi Yudhotomo² } \\
{ }^{12} \text { Universitas Nahdlatul Ulama Sidoajo Jawa Timur, Indonesia } \\
\text { yunipurnama677@gmail.com }\end{array}$} \\
\hline INFO ARTIKEL & ABSTRAK/ABSTRACT \\
\hline $\begin{array}{l}\text { Histori Artikel : } \\
\text { Tgl. Masuk : } 02 \text { Agustus } 2019 \\
\text { Tgl. Diterima : } 28 \text { Agustus } 2019 \\
\text { Tersedia Online : } 30 \text { September } 2019 \\
\text { Keywords: } \\
\text { Interactive Media, Tax, Student }\end{array}$ & $\begin{array}{l}\text { The purpose of this study was to determine the effect of } \\
\text { learning media based of macromedia flash on the } \\
\text { knowledge of students high school in Sidoarjo Regency. } \\
\text { The type of research carried out was quasi-experimental. } \\
\text { The study was designed with two treatment classes, namely } \\
\text { the experimental class and the control class. The sample } \\
\text { used as subjects in this study were two high schools in } \\
\text { Sidoarjo Regency, East Java. The research subjects are } \\
\text { class XI PGRI High School and Sidoarjo High School. Each } \\
\text { school was chosen by two classes which were used as the } \\
\text { experimental class and the control class. The research } \\
\text { instrument used was a test instrument about tax material. } \\
\text { The research data were analyzed using the parametric } \\
\text { statistical test with a t-test that aims to determine the } \\
\text { average difference of each class of research. The results } \\
\text { showed that: there was a significant difference between the } \\
\text { knowledge of students who were given learning assisted by } \\
\text { interactive media based on macromedia flash tax and } \\
\text { conventional learning. Results of t-test analysis show that } \\
\text { the significance value is less than alpha 0.05. }\end{array}$ \\
\hline
\end{tabular}

\section{PENDAHULUAN}

Pajak merupakan salah satu sumber pendapatan Negara yang digunakan untuk belanja Negara. Pembangunan insfrastruktur dan belanja pemerintah lainnya berasal dari pendapatan pajak. Hal ini menuntut pemerintah untuk memaksimalkan pendapatan dari pajak. Menurut data Kemenkeu (2018) penerimaan pajak pada tahun 2018 sudah mmencapai Rp 1.315,9 triliun, atau hanya $92 \%$ realisasi dari target APBN 2018 sebesar Rp 1.424 triliun. Hal ini menunjukkan bahwa penerimaan pajak sudah tergolong tinggi jika ditinjau dari target.

Upaya pemerintah dalam meningkatkan pendapatan melalui pajak diawali dengan penerapan program tax amnesty pada tahun 2017. Selain itu, upaya Direktorat jendral pajak dengan melakukan pemantauan sumber pajak yang semakin disiplin juga dapat meningkatkan pendapatan pajak. Penetapan aturan dan regulasi yang trasnsparan dapat meningkatkatkan minat masyarakat untuk patuh pajak.

Upaya lainnya yang dapat dilakukan adalah dengan meningkatkan kesadaran masyarakat untuk menjadi wajib pajak yang taat aturan. Kesadaran tersebut dapat dimulai dari jenjang pendidikan baik menengah ataupun jenjang sekolah tingkat atas. Pada pembelajaran di sekolah merupakan langkah yang tepat untuk memberikan kesadaran masyarakat sejak dini tentang pajak. 
Kenyataan menunjukkan bahwa di sekolah penyampaian pajak pada mata pelajaran ekonomi tidak belum memberikan kesan kepada siswa untuk melaksanakan pada kehidupan seharihari. Pembelajaran yang umum dilakukan adalah dengan memberikan materi dengan metode ceramah kemudian dilakukan pengujian dengan tes.

Hasil observasi awal penulis terhadap SMA di Kabupaten Sidoarjo yang telah mempelajari materi pajak. Beberapa rangkuman hasil observasi menunjukkan bahwa siswa cendrung lupa materi yang telah diberikan pada kelas XI. Selain itu, penulis juga memberikan salah satu kasus perhitungan besar pajak PPh dari seseorang pekerja dengan penghasilan tertentu, namun hanya beberpa siswa yang masih ingat perhitungannya.

Dalam memberikan pengalaman kepada siswa tentang materi pajak dimana siswa dapat melakukan simulasi secara langsung dalam menghitung jumlah pajak yang akan dibayar. Pengalaman tersebut dapat difasilitasi dengan menggunakan media pembelajaran. Salah satu media yang dapat digunakan adalah media animasi flash. Materi yang didesain dengan macromedia flash akan menunjang pemahaman siswa yang mendapat simulasi perhitungan secara langsung. Hasil penelitian yang dilakukan Yuni (2018) tentang pelatihan pajak menggunakan media belajar berbasis macromedia flash menunjukkan adanya peningkatan pemahaman siswa SMP tentang pajak sebelum dan sesudah diberikan pelatihan. Selain itu, rata-rata hasil tes pengetahuan tentang pajak mencapai 8,3.

Sehingga dilaksanakan penelitian dengan menggunakan medi interaktif materi pajak berbasis macromedia flash untuk menunjang pengetahuan siswa SMA tentang pajak.

\section{KERANGKA TEORITIS DAN PENGEMBANGAN HIPOTESIS}

\section{Kerangka Teoritis}

Definisi pajak menurut Pasal 1 UU

No.28 Tahun 2007 tentang Ketentuan umum dan tata cara perpajakan, pajak adalah kontribusi wajib kepada negara yang terutang oleh orang pribadi atau badan yang bersifat memaksa berdasarkan Undang Undang, dengan tidak mendapat timbal balik secara langsung dan digunakan untuk keperluan negara bagi sebesar-besarnya kemakmuran rakyat. Menurut Waluyo (2011) pajak adalah iuran kepada negara yang dapat dipaksakan yang terutang oleh yang wajib membayarnya menurut undang-undang dengan tidak mendapat prestasi kembali yang langsung dapat ditunjuk dan berguna untuk membiayai pengeluaran-pengeluaran umum yang berhubungan dengan tugas-tugas negara untuk menyelenggarakan pemerintahan.

Dalam menyampaikan materi pajak agar mudah diterima siswa dapat menggunakan media pembelajaran. Arsyad (2013) mengemukakan bahwa media pembelajaran adalah segala sesuatu yang dapat digunakan untuk menyampaiakan pesan atau informasi dalam proses belajar mengajar sehingga dapat merangsang perhatian dan minat siswa dalam belajar. Media pembelajaran dapat digunakan untuk menciptakan kondisi pembelajaran yang nyata. Selanjutnya menurut Daryanto (2013: 5) bahwa proses belajar mengajar hakekatnya adalah proses komunikasi, penyampaian pesan dari pengantar ke penerima.

Dalam proses belajar terdapat pesan yang hendak disampaikan. Pesan tersebut dapat berupa informasi yang mudah diserap oleh penerima, namun juga dapat berupa infomrasi yang abstrak atau sulit untuk diterima. Ketika pesan yang disampaikan tidak dapat diterima oleh penerima maka diperlukan solusi yang dapat mengantarkan pesan tersebut. Media merupakan sarana atau alat yang digunakan untuk mengantarkan pesan dari pengirim ke penerima pesan, dengan tujuan untuk mengingkatkan pemahaman penerima pesan tersebut. Hal ini mendukung pentingnya media salah satunya dalam menyampaikan materi pajak.

Media yang dapat digunakan macromedia flash. Menurut Aaron (2011) 
terdapat beberapa keunggulan dari program/software Adobe Flash sebagai berikut.

a. Dapat membuat tombol lebih dinamis dengan memaksimalkan action script

b. Dapat membuat obyek 3 dimensi.

c. Beberapa tool grafis yang terdapat pada software grafis Adobe diadaptasi dan dimaksimalkan di software Adobe Flash.

d. Tampilan interface yang lebih simple dan cukup mudah dicerna.

e. Membuat gerakan animasi dengan mengikuti alur yang telah ditetapkan sebelumnya.

f. Dapat dikonversi dan dipublikasikan ke dalam beberapa tipe yang cukup umum di penggunaan software lain, seperti .swf, .html, .gif, .jpg, .png, .exe, .mov dan lain sebagainya.

\section{Pengembangan Hipotesis}

Pembelajaran yang baik adalah pembelajaran yang dapat memfasilitasi siswa dalam memahami materi. Alat atau media yang dapat menjembatani siswa memahami materi sangat perlu digunakan. Salah satu media yang mudah dan dapat memfasilitasi siswa dalam penemuan konsep adalah macromedia flash. Pendesaian media pembelajaran dengan macromedia flash diasumsikan dapat meningkatkan hasil atau pengetahuan siswa tentang materi. Hipotesis yang dikembangkan pada penelitian ini adalah: terdapat perbedaan signifikan antara pengetahuan siswa yang diberikan pembelajaran berbantuan media interaktif pajak berbasis macromedia flash dengan pembelajaran konvensional.

\section{METODOLOGI PENELITIAN}

Metode penelitian merupakan eksperimen semu (quasi eksperiment). Penelitian difokuskan pada pengaruh pembelajaran dengan menerapkan media interaktif berbasis macromedia flash terhadap pengetahuan siswa SMA pada Materi Pajak. Subjek dalam penelitian ini adalah siswa SMA Kelas XI yang tediri dari dua sekolah, yaitu SMA PGRI dan SMA Unggala di Kabupaten Sidoarjo. Penelitian didesain dengan kelas eksperimen dan kelas kontrol.

Pemilihan sampel penelitian dilaksanakan dengan teknik purvosive sampling. Pemilihan sekolah sampel berdasarkan jarak dari tempat kerja peneliti. Pada setiap sekolah sasaran penelitian dipilih masing-masing dua kelas secara random sampling untuk dipilih sebagai kelas yang diberikan pembelajaran menggunakan media berbasis macromedia flash (kelas eksperimen) dan dengan pembelajaran konvensional (kelas kontrol).

Instrumen penelitian yang digunakan adalah instrument tes yang terdiri dari 15 soal pilihan ganda. Analisis data penelitian yang dilakukan terdiri dari dua, yaitu: (1) analisis statistik deskriptif dan, (2) analisis statistik infrensial. Analisis statistik deskriptif dilakukan untuk mendeskripsikan hasil penelitian secara deskriptif. Selanjutnya, analisis data statistik infrensial dilakukan dengan uji paired sample $t$ test. Analisis statistik dilakukan dengan menggunakan bantuan program SPSS.

UJi paired sample t-test digunakan untuk menguji perbedaan dua sampel yang berpasangan.Pengujian dilakukan dengan berbantuan program SPSS. Dasar pengambilan keputusan untuk menerima atau menolak hipotesis pada uji paired sampel t-test adalah sebagai berikut.

(1)Jika probabilitas (Asymp.Sig) $<0,05$ maka hipotesis diterima.

Jika probabilitas (Asymp.Sig) $>0,05$ maka hipotesi ditolak.

\section{HASIL DAN PEMBAHASAN}

\section{Deskripsi Pelaksanaan Penelitian}

Pelaksanaan penelitian dilakukan dengan desain eksperimen semu dimana peneliti menggunakan kelas yang sudah ada tanpa menyusun kelompok baru. Penelitian dilaksanakan di dua sekolah tingkat SMA, yaitu SMA PGRI 5 dan SMA Unggala Sidoarjo. Pada masing-masing sekolah dipilih dua kelas penelitian yang diberikan nama kelas eksperimen dan kelas kontrol. Subjek sasaran penelitian adalah siswa kelas XI IPS di setiap sekolah. Penelitian dilaksanakan dengan 
cara kolaborasi dengan guru mata pelajaran akuntansi. Pelakasaan dengan memberikan materi kepada siswa tentang pajak.

Penelitian dilakasanakan dalam beberapa tahap, yaitu: (1) penyusunan media, (2) Survei sasaran penelitian, (3) koordinasi, dan (4) pelaksanaan, (5) analisis data penelitian. Pembelajaran diberikan selama 90 menit dengan cara presentasi dan diskusi. Presentasi dilaksanakan selama 60 menit dengan menggunakan media belajar dengan berbantuan macromedia flash. Materi yang diberikan adalah tentang pajak-pajak dasar serta contoh perhitungan pajak. Siswa juga dibekali dengan informasi manfaat pajak dalam membangun fasilitas umum. Setelah pembelajaran dilanjutkan dengan tanya jawab dan siswa dipandu untuk menghitung besar pembayaran pajak dengan memberikan contoh penghasilan, dan besar pajak yang dikenakan dari penjualan, pembelian, penghasilan.

\section{Deskripsi Data Hasil Penelitian}

Data hasil penelitian yang dianalisis ditinjau dari dua aspek, yaitu data pengetahuan siswa tentang pajak dan data angket respon siswa. Data diperoleh dari setiap kelas penelitian dengan memberikan posttest pada masing-masing kelas setelah diberikan perlakuan. Pada kelas eksperimen dilakukan pembelajaran berbantuan media pajak menggunakan macromedia flash dan kelas kontrol disampaikan materi pajak secara konvensional, yaitu ceramah. Pemberian postest di akhir pertemuan berupa tes pengetahuan siswa tentang pajak.

Data pengetahuan siswa tentang pajak diperoleh dari tes berupa pilihan ganda tentang materi pajak. Instrumen untuk mengukur pengetahuan pajak berupa tes dengan pilihan ganda yang berjumlah 15 soal. Soal disusun berdasarkan materi dasar tentang pajak. Data dideskripsikan berdasarkan nilai tertinggi, nilai terendah, dan nilai rata-rata dari masing-masing kelas untuk masingmasing kelas penelitian. Deskripsi data hasil tes kemampuan pajak pada kelas penelitian di SMA PGRI 5 tersaji seperti pada tabel berikut.
Tabel 1. Deskripsi Statistik pengetahuan siswa SMA PGRI 5

\begin{tabular}{|l|c|c|}
\hline \multirow{2}{*}{ Nilai } & \multicolumn{2}{c|}{ Kelas Penelitian } \\
\cline { 2 - 3 } & Eksperimen & Kontrol \\
\hline Maksimum & 100 & 86,67 \\
\hline Minimum & 53,33 & 33,33 \\
\hline Rata-rata & 81,15 & 62,62 \\
\hline Standar Deviasi & 13,57 & 13,97 \\
\hline \% Ketuntasan & 73,31 & 35,71 \\
\hline
\end{tabular}

Berdasarkan tabel di atas dapat diketahui bahwa pada kelas eksperimen nilai terendah sebesar 53,33 dengan nilai tertinggi 100. Data juga menunjukkan bahwa ketuntasan sebesar 73,31\% (23 siswa) yang memiliki nilai di atas 72 (KKM) sekolah. Berbeda dengan hal tersebut pada kelas kontrol nilai maksimum hanya sebesar 86,67 dengan rata-rata 62,62. Selanjutnya ditinjau dari ketuntasan pada kelas kontrol hanya mencapai persentase sebesar 32,71 yang nilainya di atas KKM (72).

Berdasarkan data hasil penelitian pada SMA PGRI 5 diketahui bahwa terdapat perbedaan data pengetahuan siswa secara rata-rata antara kelas eksperimen dan kelas kontrol. Perbandingan hasil pengetahuan siswa antara kelas eksperimen dan kelas kontrol pada SMA PGRI dapat dilihat pada gambar berikut.

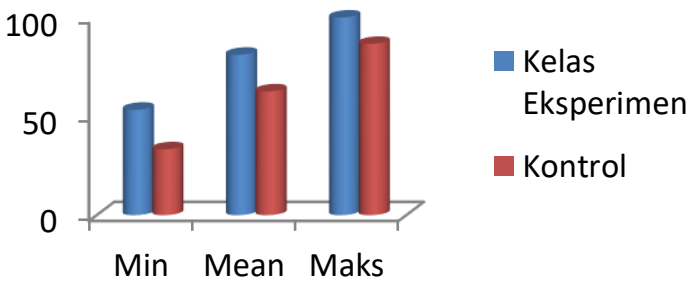

Gambar 1. Perbandingan Data Kelas eksprimen dan Kontrol SM PGRI

Selanjutnya, hasil analisis pada kelas penelitian kedua, yaitu SMA unggala dideskripiskan pda tabel berikut.

Tabel 2. Deskripsi Statistik pengetahuan siswa SMA Unggala

\begin{tabular}{|l|c|c|}
\hline \multirow{2}{*}{\multicolumn{1}{|c|}{ Nilai }} & \multicolumn{2}{c|}{ Kelas Penelitian } \\
\cline { 2 - 3 } & Eksperimen & Kontrol \\
\hline Maksimum & 100 & 80,00 \\
\hline Minimum & 60,00 & 33,33 \\
\hline Rata-rata & 81,26 & 57,14 \\
\hline Standar Deviasi & 11,66 & 12,92 \\
\hline \% Ketuntasan & 73,31 & 35,71 \\
\hline \multicolumn{2}{|c}{}
\end{tabular}


Hasil analisis data pengetahuan siswa pada kelas eksperimen dan kontrol SMA Unggala menunjukkan bahwa nilai maksimum sebesar 100 pada kelas eksperimen dan kontrol sebesar 80. Nilai rata-rata kelas eksperimen lebih tinggi dari kelas kontrol yaitu sebesar 81,26 dan pada kelas kontrol sebesar 57,14 . Hasil analisis pada kedua kelas secara detail digambarkan pada grafik berikut.

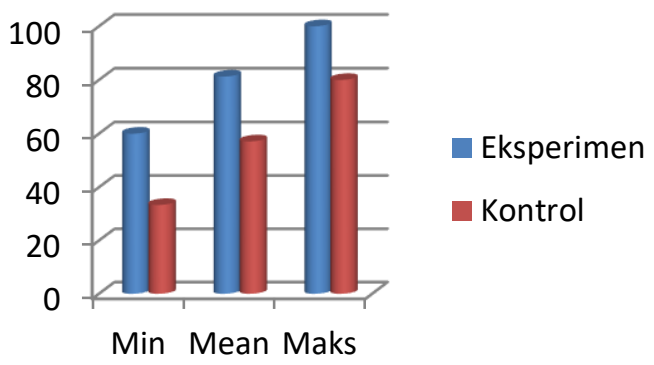

Gambar 2. Perbandingan Data Kelas eksprimen dan Kontrol SMA Unggala

\section{Hasil Analisis Pengujian Hipotesis}

Hipotesis yang diujikan dalam pelaksanaan penelitian ini terdiri dari dua, yaitu:Hasil analisis menunjukkan terdapat perbedaan rata-rata pemahaman siswa tentang pajak sebelum dan sesudah pelatihan. Untuk menganalisis perbedaan tersebut secara statistik dilakukan dengan analisis uji t. Adapun hipotesis yang diuji sebagai berikut.

$\mathrm{H}_{1}$ : Terdapat perbedaan signifikan antara pengetahuan siswa yang diberikan pembelajaran berbantuan media interaktif pajak berbasis macromedia flash dengan pembelajaran konvensional

$\mathrm{H}_{2}$ : Terdapat perbedaan signifikan antara respon siswa yang diberikan pembelajaran berbantuan media interaktif pajak berbasis macromedia flash dengan pembelajaran konvensional

Dengan kriteria pengujian: Jika pada hasil taraf signifikan $<\alpha=0,05$ maka Hipotesis diterima. signifikan $>\alpha=0,05$ maka Hipotesis ditolak. Hasil uji $t$ data pengetahuan siswa seperti berikut.
Tabel 3. Data Hasil Uji T Pengetahuan siswa Subjek Penelitian

\begin{tabular}{|l|c|c|c|}
\hline \multicolumn{1}{|c|}{ Kelas } & t & Df & Sig \\
\hline $\begin{array}{l}\text { Eks-Kont } \\
\text { SMA PGRI }\end{array}$ & 5,35 & 27 & 0,000 \\
\hline $\begin{array}{l}\text { Eks-Kont } \\
\text { SMA Unggala }\end{array}$ & 6,79 & 21 & 0,000 \\
\hline
\end{tabular}

Tabel uji t di atas menunjukkan pada pemahaman siswa sebelum dan sesudah pelatihan dengan nilai signifikan ,000< 0,005 . Dari hasil tersebut menunjukkan Terdapat perbedaan signifikan antara pengetahuan siswa yang diberikan pembelajaran berbantuan media interaktif pajak berbasis macromedia flash dengan pembelajaran konvensional. Selanjutya, hasil pengujian hipotesis

\section{KESIMPULAN \\ Kesimpulan Penelitian}

Berdasarkan hasil penelitian dan analisis data hasil penelitian diperoleh kesimpulan bahwa terdapat perbedaan signifikan antara pengetahuan siswa yang diberikan pembelajaran berbantuan media interaktif pajak berbasis macromedia flash dengan pembelajaran konvensional. Hal ini ditunjukkan dari nilai rata-rata pengetahuan siswa pada kelas eksperimen lebih tinggi dari kelas kontrol. Selain itu, hasil uji t menunjukkan bahwa nilai signifikansi kurang dari alpha 0,05 sehingga hipotesis diterima.

\section{Saran Penelitian}

Berdasarkan pelaksanaan pelatihan pemahaman pajak siswa menggunakan media pembelajaran berbasisis macromedia flash, dapat disarankan halhal sebagai berikut:

a. Guru dapat menambahkan materi tentang pajak secara umum agar pemahaman siswa tentang pajak lebih luas

b. Guru dapat menambah latihan-latihan atau perhitungan pajak dalam kehidupan sehari-hari

c. Pemanfaatan media berbasis komputer dapat dikembangkan secara online sehingga mudah diakses oleh siswa melalui internet. 
IMPLIKASI

DAN

\section{KETERBATASAN}

Implikasi Penelitian

Implikasi dari hasil penelitian ini adalah menumbuhkan kesadaran kepada siswa tentang fungsi pajak dan kewajiban wajib pajak. Hasil penelitian ini dapat dijadikan referensi oleh pemerintah dalam melakukan penyuluhan pajak kepada masyarakat yang sasarannya kaum mileneal.

\section{Keterbatasan Penelitian}

Keterbatasan dari penelitian ini adalah waktu pelaksanaan. Dalam pelaksanaan yang melibatkan siswa harus disesuaikan dengan waktu di sekolah. Selain itu, subjek penelitian hanya terbatas pada siswa dari dua sekolah, yaitu sekolah SMA PGRI dan SMA Unggala.

\section{REFERENCES}

Aaron, J. 2011. Jurus Kilat Jago Adobe Flash. Yogyakarta: Dunia Komputer Arsyad, 2013. Media Pembelajaran. Jakarta: PT Raja Grafindo Persada

Daryanto. 2013. Media Pembelajaran Perannya Sangat Penting Dalam Mencapai Tujuan Pembelajaran. Yogyakarta: GAVA MEDIA

Direktorat Jenderal Pajak. 2018. Laporan pendapatan pajak negara

Kementerian Keuangan Republik Indonesia. 2018. Anggaran Pendapatan dan Belanja Negara (APBN).

Direktorat Jenderal Pajak, Undangundang Nomor 28 Tahun 2007 tentang Perubahan Ketiga atas Undangundang Nomor 6 tahun 1983 tentang Ketentuan Umum dan tata Cara Perpajakan

Mardiasmo.2011. Perpajakan Edisi Revisi. Yogyakarta: Penerbit Andi

Waluyo. 2011. Perpajakan. Jakarta: Salemba Empat 